we find reference to the "six year old recommendations of the Littlewood committee". A moment's thought suffices to reject the possibility in this context of six recommendations, each a year old. Yet why must we be constantly brought up against these small ambiguities, all of which would vanish on the appearance of correctly placed hyphens? In this case the two meanings are rendered by "six-year-old" and "six year-old".

A traditional ambiguity is to be found in the title on p. 432: "Sex Determination in Birds and Mammals". The Concise Oxford Dictionary actually lists the two conflicting meanings of "determine" consecutively: "give decision; be the decisive factor in regard to". Inspection of the article showed me that I had taken the wrong meaning in supposing the authors to have new ideas on finding out whether individual birds are male or female. Therefore a better title might have been "Sex Regulation. ..", whatever the customary usage among biologists may be.

Of these two kinds of ambiguity the first is by far the most pervasive and deleterious. Nature is difficult enough to understand without these unnecessary obstacles.

Yours faithfully, GARRY THOMSON

The Athenaeum,

Pall Mall,

London $S W 1$

\section{Braille Reading}

SIR,--Perhaps I may be permitted to make two points on the report by Hermelin and O'Connor on braille reading (Nature, 231, 470; 1971).

In a survey I made three years ago on methods of teaching braille to newly blinded adults and adolescents, one of the questions asked teachers to state what advice they gave learners as to which hand to use in reading. Two of the 67 respondents stated that they advised the use of the right hand alone; none recommended the left hand alone; 29 recommended the use of both hands; 36 allowed the learner to make his own decision.

The justification for the "scissors" movement described by Hermelin and
O'Connor is that while the right hand is completing the second half of a line, the left hand can be dropped down to the next line, thus ensuring a quicker rate of reading. As only about $30 \%$ of all braille readers read at more than 100 words per minute, it is clearly desirable to develop the use of both hands so that as little time as possible is lost in moving from line to line. One of the most readily observable characteristics that differentiates the fast braillist from the slow is the extent to which the former uses both hands. To take advantage of the Hermelin and O'Connor findings we should probably need to read in a right to left direction so that the good hand, the left, can do the reading while the less efficient right drops down to the next line to act as a marker for the returning left!

Yours faithfully,

\section{J. TOBIN}

Director,

Research Centre for the

Education of the Visually

Handicapped,

50 Wellington Road,

Edgbaston, Birmingham B15 $2 E P$

\title{
Obituary
}

\section{Professor S. Lawrence}

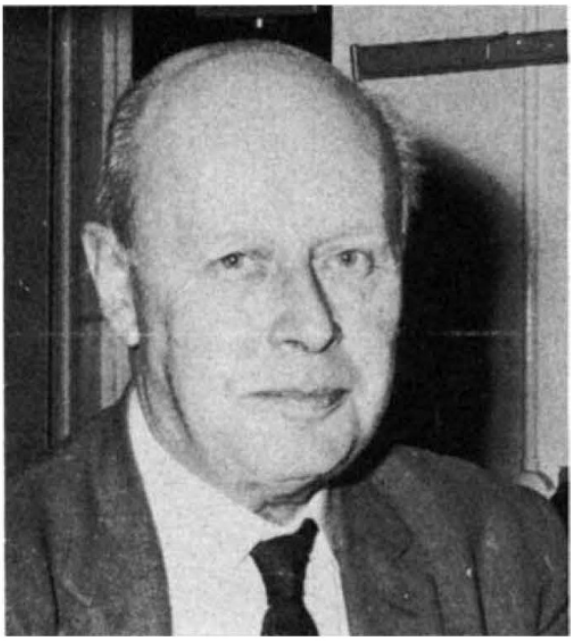

StUART LAWRENCE was born in London on June 28, 1902, and died in Sheffield on February 22, 1971. His early education at Christ's Hospital School was continued with evening classes at Battersea Polytechnic, but the moulding of the essential personality of Lawrence the scientist really began when Sir James Dewar recruited him as an assistant at the Royal Institution, where he remained until 1929. During that time he rubbed shoulders with the famous, witnessed an important phase in the development of X-ray analysis, and acquired a useful familiarity with the standard techniques of a physical science laboratory. In 1929 he moved to Cambridge. While a lively interest in photography produced The Scientific Photographer (1941), it was his other early book on Soap Films (1929) which showed where his heart really lay; he was already an experienced investigator in that field at the time of his move to the Colloid Science Laboratory at Cambridge, on a senior D.S.I.R. award. At Cambridge he proceeded directly to the Ph.D. degree and subsequently to the Sc.D. His F.R.I.C. dates from 1944.

During the war, scientific advisory work for the Admiralty took him to sea to examine at first hand the problems of de-icing and seawater emulsions in fuel oils and sent him finally, with the rank of commander, on a scientific tour of devastated Europe. That work led to two by-products: a Beilby award in 1948 and a fund of sea stories with which to lace his general conversation.

He joined the Chemistry Department of the University of Sheffield as a Senior Lecturer in 1947, but his distinction as a researcher was recognized by the award of a readership in 1949 and of a personal chair in 1966, a year before his retirement. He will be remembered with great affection by his colleagues, his research collaborators, and by many generations of undergraduates for his was a personality that could not be overlooked: it had an endearingly comic streak that was perhaps unsuspected from a chance professional encounter with the great domed head and the mock-pompous expression he reserved for special occasions. His tremendous reserves of courage were shown in his attitude towards the amputation of a leg in 1964: within four or five months he was already flying to foreign parts to fulfil his lecturing and other commitments.

Though he initiated quantitative investigations from time to time-for example, in his studies of viscosity with A. Jobling and of coagulation with $\mathbf{O}$. S. Mills-his great strength lay in the intuitive feeling he had for the physical nature of colloidal and liquid crystal systems. He was happiest amongst thermostats, test-tubes and microscope slides, and his enthusiasm for the polarizing microscope and the myelinic figures he saw with it often suggested the thought that, if he had not been a distinguished colloid scientist, he might well have become an outstanding descriptive biologist. 